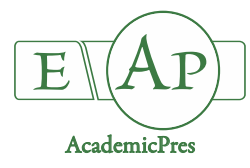

\title{
Foliar Micromorphology and Histochemical Localization of Specific Metabolites in the Leaves of Celosia argentea $\mathrm{L}$.
}

\author{
Oluwafunmilayo Dorcas ADEGBAJU, Gloria Aderonke OTUNOLA* \\ Anthony Jide AFOLAYAN
}

University of Fort Hare, Medicinal Plants and Economic Development (MPED) Research Centre, Department of Botany, Alice 5700, Eastern

Cape Province,SouthAfrica; funmaj2005@gmail.com; gotunola@ufh.ac.za $\left({ }^{*}\right.$ Correspondingauthor $)$;afolayan@ufh.ac.za

\begin{abstract}
Celosia argentea is an essential vegetable that is cultivated in the western part of Africa. This species has a growing reputation for its role in alleviating nutritional challenges and has found great application as herb of therapeutic importance in many regions of the world. This study investigated the foliar micromorphology and the histochemistry of Celosia argentea. Scanning electron microscopy (SEM), energy dispersive X-ray (EDX) spectrometry and staining agents were used to evaluate the micromorphology of the plant. The result revealed sunken amphistomatic stomata distribution on both surfaces of the leaf. Anomocytic and anisocytic stomata complexes were also observed on both epidermal surfaces. A definitive protuberance was observed on the polar end of the adaxial stomata. Stomata apparatus was ellipsoidal with a mean length of $19.60 \pm 0.56 \mu \mathrm{m}$, while the mean stomata densities on the adaxial and abaxial surfaces were $83.5 \pm 2.12 \mathrm{~mm}^{-2}$ and $194.18 \pm 3.70 \mathrm{~mm}^{-2}$ respectively. Trichomes (with a length of $100.94 \pm 9.44 \mu \mathrm{m}$ ) were sparsely distributed on both surfaces; glandular trichomes were observed only on the abaxial surface. The EDX spectrometry revealed the presence of iron, oxygen, sodium, calcium, potassium and sulphur as the major elements on the leaf, while histochemical tests revealed the presence of polyphenols, starch and lipids. Our results could be used to support and validate the information database on the anatomy of Celosia argentea.
\end{abstract}

Keywords: Celosia argentea; foliar epidermis; histochemistry; stomata; trichome

\section{Introduction}

The genus Celosia belongs to the family Amaranthaceae and is represented by over 60 species. Species of this genus are found in all continents of the world but majorly in Asia, North America and Africa (Schliemann et al., 2001). They are commonly referred to as Cockscomb because of their flower heads, which look like the comb on a cock's head. Other names for the flowers include wool-flower, quail grass, wheat straw, flamingo feather, flame-head and velvet flower. Most members of this genus are widely grown as vegetables while others are used as ornamentals because of their brightly colored and enthralled inflorescence (Gottshalk and Wolff, 2012). Among the garden varieties, the color of inflorescence varies from yellow to various shades of red and sometimes violet in some regions of the world (Ogungbenle and Otemuyiwa, 2015). They are mostly herbaceous annual plants; the leaves are simple, alternate, linear to lanceolate, stipules; petioles indistinctly demarcated, tapering at the base and pinnately veined. Among the members of these species, Celosia argentea L.
(Fig. 1) is the most popular as it is cultivated as a vegetable because of its numerous nutritional and pharmacological uses (Gupta et al., 2005).

Celosia argentea is an essential vegetable that is cultivated in the western part of Africa. This species has a growing reputation for its role in alleviating nutritional challenges and has also found great application as a herb of therapeutic importance in many regions of the world (Gupta et al., 2005; Adedidran et al., 2015)

Apart from the culinary uses of $C$. argentea, it is widely used in traditional medicine for the treatment of various disorders such as diarrhea, jaundice, mouth sores, gonorrhea, uterine bleeding, hemorrhoids and inflammation (Zheng and Xing, 2009; Varadharaj and Munyiyappan, 2017). Studies on the pharmacological activities of $C$. argentea have reported the anti-diabetic, antihelminthic, antioxidant, antimicrobial and antibacterial potentials of this plant (Sharma et al., 2010; Wu et al., 2011). Chemical analysis of this species indicated the presence of bioactive compounds like phenols, saponins, cyclopeptides (Xue et al., 2011; Molehin et al., 2014; Okpako and Ajibesin, 2015) among others. 
There are various reports on the nutritional values, phytochemical constituents and pharmacological activities of the species. However, there are scanty reports on the anatomical and morphological features of $C$. argentea. With the aid of an ocular microscope, the petiole anatomy and the arrangement of crystals in the leaf blade of some species of Celosia have been investigated (Illoh, 1995). Furthermore, general anatomical accounts of some species of the Amaranthaceae family like the amphistomatic leaf, presence of raphoids, styloids and crystal sand have also been documented (Metcalfe and Chalk, 1979; Ogundipe and Kadiri, 2013). However, literatures on distinct ultrafeatures of $C$. argentea are very few.

Ultrastructural features of different plants parts have been used as an essential tool in systematics and palaeobotanical studies. Vegetative anatomical traits are of great ecological and physiological significance especially in validating plant derived substances for medicinal uses so as to avoid substitution with closely related species (Albert and Sharma, 2013). Therefore, critical evaluations of leaf micro morphological features are very useful when integrated with morphological data for the identification of any plant species. Kantachot et al. (2007) stated that leaf anatomical data support morphological evidence for species identification and taxa separation at the generic level.

The leaves of most members of the Amaranthaceae family are versatile in the production of secondary metabolites such as flavonoids, phenolic acids, saponins and tannins (Iwu, 2014), which have therapeutic properties. Recently, histochemical features are frequently been used in identifying and characterizing these metabolites as well as solving taxonomic problems. Furthermore, histochemical studies are pivotal for the identification and distribution of chemical constituents in different organs of the plant including both the vegetative and reproductive organs (Krouk et al., 2010). The presence of starch grains, phenolic compounds and lignins have been reported for some members of the Amaranthaceae family like Cyathula prostrata and Dysphania ambrosioides through histochemicial screening (Sereena and Sreeja, 2014; Sa et al., 2016). Apart from phytochemical screening reports on $C$. argentea, the histochemistry of this species for taxa delimitation is also very scanty.

The present study aimed to investigate the micromorphological, histochemical and ultrastructural features of the leaves of Celosia argentea in a bid to provide additional information relevant for taxonomic documentation on the foliar epidermal features of this species. It is anticipated that the results will expand the scope of knowledge of this species.

\section{Materials and Methods}

\section{Sample collection}

Celosia argentea Lin. were grown from seeds in plastic pots filled with compost soil (Kanya Nursery, Alice Eastern Cape, South Africa) at the green house of Botany Department University of Fort Hare, Alice, 5700 Eastern
Cape, South Africa. The university geographical location lies at latitude $32^{\circ} 47^{\prime}-19^{\circ} 26^{\prime}$ S; longitude $26^{\circ} 50^{\prime}-42^{\circ} 306^{\prime} \mathrm{E}$ and at altitude of 514.70 meters above sea level. The plants were irrigated daily and weeding was done frequently as per the emergence of weeds. A voucher specimen (Ade/med/2017/01) at maturity stage was deposited at the Giffen Herbarium, University of Fort Hare.

\section{Light microscopy}

Fresh matured leaves were harvested at five weeks old (Fig. 1). Samples of leaf surface with approximately $0.5 \mathrm{~cm}^{2}$ were peeled off from the adaxial and abaxial surfaces to obtain the epidermal peel. The peels were stained with Nile blue sulfate solution to expose the tissues. The samples were washed with distilled water until the tissues were completely translucent. Samples were mounted on a glass slide and observed under a Zeiss light microscope. The slides were viewed using a UOP photomicroscope and results were recorded on Pro-Micro Scan Digital camera (DCM 510) as described by Akyol (2014).

\section{Scanning electron microscopy and energy dispersive $x$-ray} spectroscopy

Fresh leaves were cut into segments of 4-6 $\mathrm{mm}$ in length and fixed in $6 \% \mathrm{w} / \mathrm{v}$ glutaraldehyde at $\mathrm{pH} 7.3$ for $24 \mathrm{~h}$. The sections were rinsed with $0.05 \mathrm{M}$ sodium cacodylate buffer ( $\mathrm{pH} 7.5)$. Each sample was later rinsed in distilled water and dehydrated in graded series of ethanol $10-100 \%$ for $20 \mathrm{~min}$ per rinse. Samples were dried in a Hitachi HCP-2 Critical Point Dryer and mounted on aluminum stubs with doublesided carbon coated sputter coating with gold-palladium (Elko IB-3 Ion Coater). The samples were examined at varying magnifications using JEOL (JSM-6390LV) Scanning Electron Microscope (SEM) that was operated at $10-15 \mathrm{kV}$ accelerated voltage. Magnification at $\times 3,300$ and at $5 \mu \mathrm{m}$ on the SEM was used to determine the length of the stomata aperture, and a minimum of six stomata was observed. The energy dispersive X-ray spectroscopy (EDX) followed the same procedures as in scanning electron microscopy. Elemental analysis was done using energy dispersive X-ray analyzer (Thermo Electron Corporation, 6733B-IUUSN, USA), connected to SEM. Electron images were captured using Noran system six imaging software.

\section{Histochemical studies}

Histochemical analyses were performed on hand sections of fresh leaves samples. The following histochemical tests were carried out: Ferric chloride $\left(\mathrm{FeCl}_{3}\right)$ for polyphenols (Ferreira et al., 2017); Toluidine blue (Brien et al., 1964) for tannins; Sudan IV for lipids and Iodine potassium iodide (Momin and Kadan, 2011) for starch. Control sections (blank test) without any reagent or staining were prepared simultaneously, according to the methodology described in the protocols. The stained sections were viewed under a Zeiss light microscope and photomicrographs were taken with a DCM 510, 5 M pixels, CMOS chip digital camera fitted to the microscope. The stained sections were photographed and observed for their characteristic features. 
1130

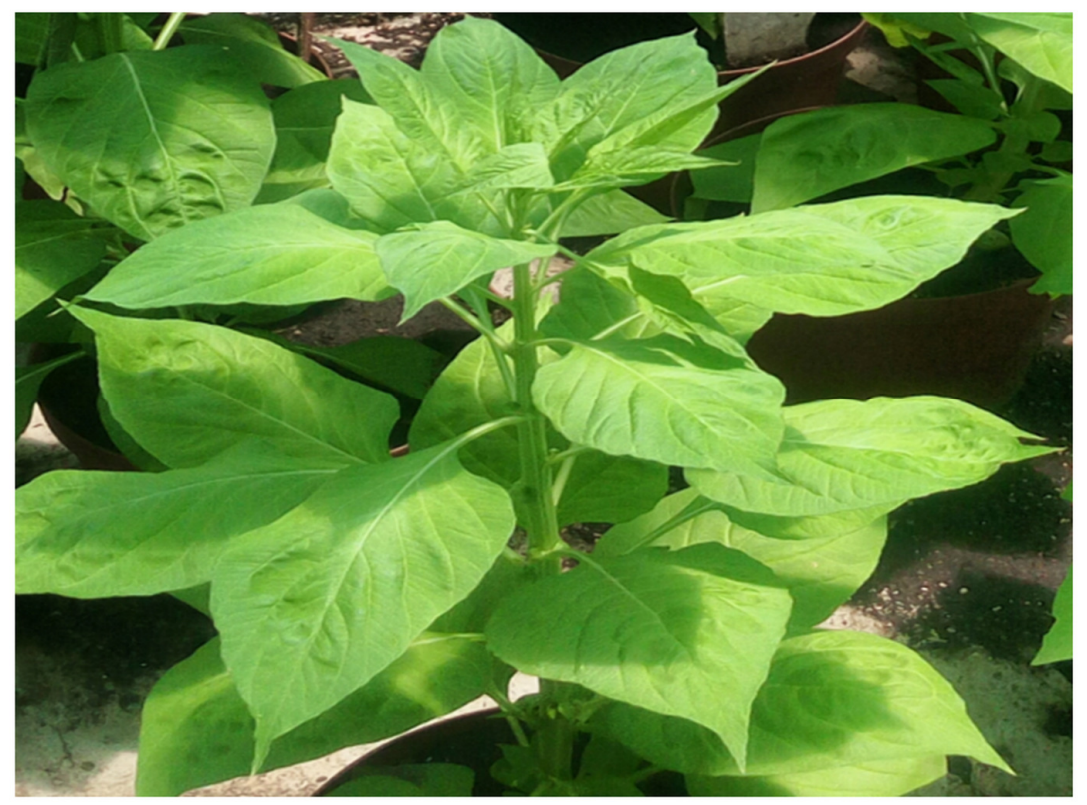

Fig. 1. Celosia argentea plant at five weeks old, grown at the green house of Botany department, University of Fort Hare, Alice, Eastern Cape, South Africa

\section{Results}

The plant used for this study was five weeks old and was grown in the green house with regulated temperature. Three samples from different leaves were used for all the investigations. The light and scanning electron microscopy revealed an anomocytic mixed with anisocytic sunken stomata. The stomata distribution was amphistomatic in nature with more stomata densely packed on the abaxial epidermis as shown in Figs. 2 and 3. The mean stomata density of the upper surface was $83.5 \pm 2.12 \mathrm{~mm}^{-2}$ and the lower surface mean density was $194.18 \pm 3.70 \mathrm{~mm}^{-2}$. The stomata apparatus was ellipsoidal and were found open on both epidermises while the stomata length was $19.60 \pm 0.56$ $\mu \mathrm{m}$ and the pore length was $16.67 \pm 1.34 \mu \mathrm{m}$ on both surfaces. Bicellular to multicellular trichomes with a length of $100.94 \pm 9.44 \mu \mathrm{m}$ were scanty on both surfaces. Glandular trichomes (Fig. 2C) were, however, observed on the abaxial surface of the leaf. The non-glandular trichomes were more or less flaccid in appearance (Fig. 2E, 2F) and are comparatively more abundant, while the glandular trichomes were capitate with single secretory cell.

On the adaxial surface (Figs. 3A, 3B) the epidermal cells were characterized by regular rectangular to polygonal anticlinal walls, compared to the irregular, rosette-shaped epidermal cells with deeply sinuous anticlinal walls (Figs. $3 \mathrm{C}, 3 \mathrm{D})$ of the abaxial surface.

The energy dispersive $\mathrm{X}$-ray (Table 1 ) revealed the presence of carbon $(\mathrm{C})$, oxygen $(\mathrm{O})$, magnesium $(\mathrm{Mg})$, sodium $(\mathrm{Na})$, nitrogen $(\mathrm{N})$, beryllium $(\mathrm{Be})$, calcium $(\mathrm{Ca})$, potassium $(\mathrm{K})$, sulphur $(\mathrm{S})$ and silicon $(\mathrm{Si})$ on both epidermal surfaces as well as on the glandular trichome. The relative proportions of the elements (Atomic \%) as shown by EDX spectroscopy for both epidermal surfaces and the glandular trichome is represented in Table 1. Chlorine was found on the abaxial surface and the glandular trichome. Figure $4 \mathrm{a}$ and $\mathrm{b}$ is representation of the EDX analyze showing the peaks corresponding to all the elements that are present on the glandular trichome and the plant sample.

Table 1. Elemental composition wt. (\%) of the foliar epidermis of $C$. argentea as revealed by EDX spectroscopy (Standard \pm error of three replications as calculated by the EDX)

\begin{tabular}{|c|c|c|c|}
\hline Elements & Abaxial wt. (\%) & Adaxial wt.(\%) & Glandular trichome wt.(\%) \\
\hline Carbon & $30.09 \pm 0.65$ & $40.35 \pm 1.14$ & $33.60 \pm 0.69$ \\
\hline Oxygen & $19.50 \pm 0.45$ & $17.62 \pm 0.41$ & $17.07 \pm 0.48$ \\
\hline Magnesium & $0.81 \pm 0.08$ & $1.18 \pm 0.09$ & $1.30 \pm 0.09$ \\
\hline Chlorine & $0.20 \pm 0.18$ & - & $0.22 \pm 0.06$ \\
\hline Sodium & $0.33 \pm 0.07$ & $0.64 \pm 0.08$ & $0.46 \pm 0.08$ \\
\hline Phosphorus & $0.89 \pm 0.12$ & $0.89 \pm 0.12$ & $1.03 \pm 0.12$ \\
\hline Nitrogen & $5.47 \pm 1.34$ & $6.54 \pm 2.37$ & $6.25 \pm 1.47$ \\
\hline Beryllium & $7.51 \pm 0.33$ & $15.79 \pm 0.82$ & $8.79 \pm 0.37$ \\
\hline Calcium & $0.78 \pm 0.09$ & $0.44 \pm 0.09$ & $0.28 \pm 0.09$ \\
\hline Potassium & $3.34 \pm 0.18$ & $4.18 \pm 0.20$ & $4.27 \pm 0.20$ \\
\hline Sulphur & $0.95 \pm 0.13$ & $0.64 \pm 0.13$ & $0.93 \pm 0.13$ \\
\hline Silicon & $0.06 \pm 0.05$ & $0.09 \pm 0.05$ & $0.05 \pm 0.05$ \\
\hline Iron & $0.034 \pm 0.10$ & $0.34 \pm 0.19$ & $0.06 \pm 0.06$ \\
\hline
\end{tabular}



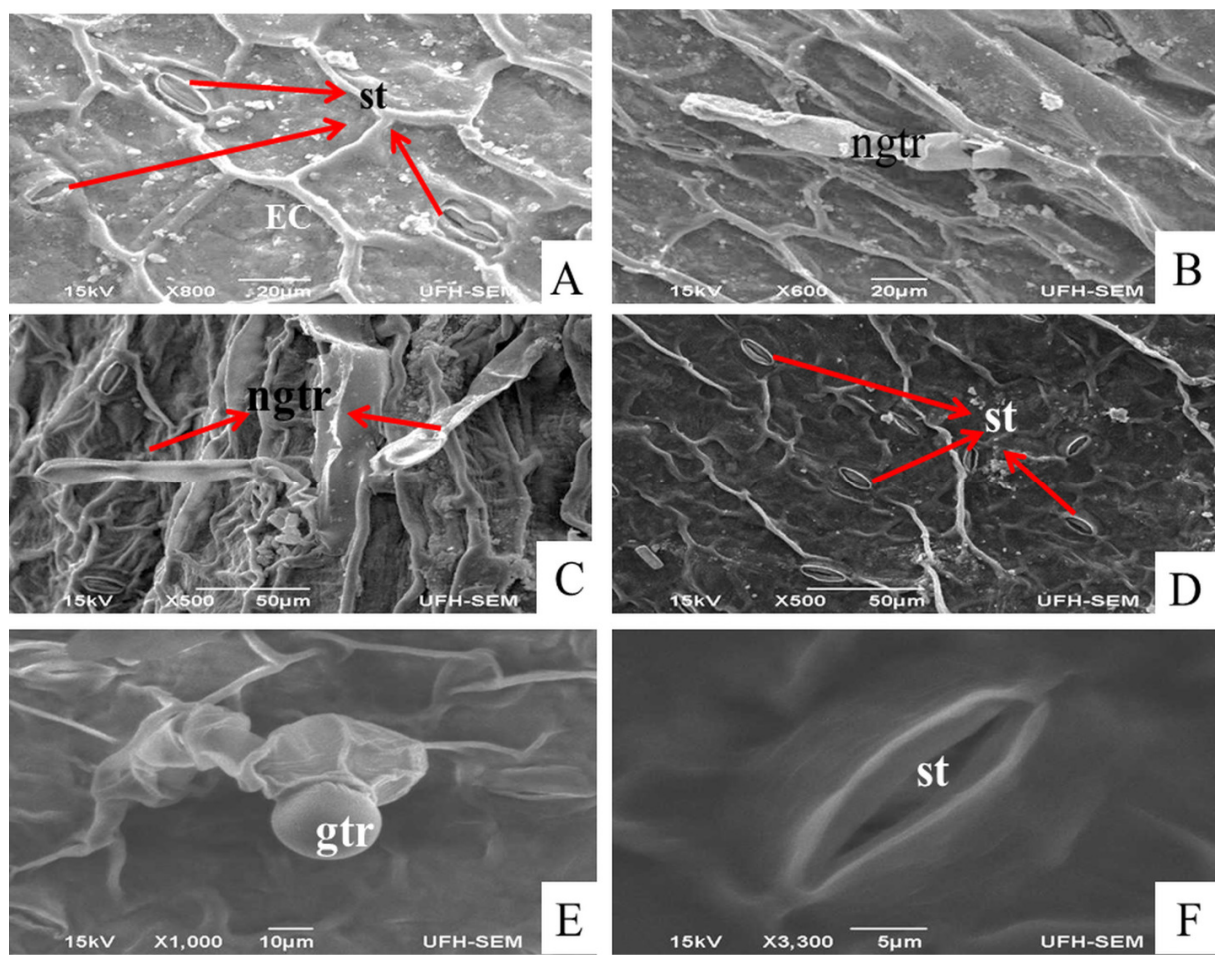

Fig. 2. Scanning electron micrographs of adaxial surface of $C$. argentea. Arrow points to trichomes and stomata (A, B and C) showing epidermal cells (EC); stomata (st), bi-cellular and multicellular non-glandular trichomes (ngtr); and abaxial surface. (D, $\mathrm{E}$ and F) showing stomata and a single celled capitate glandular trichome
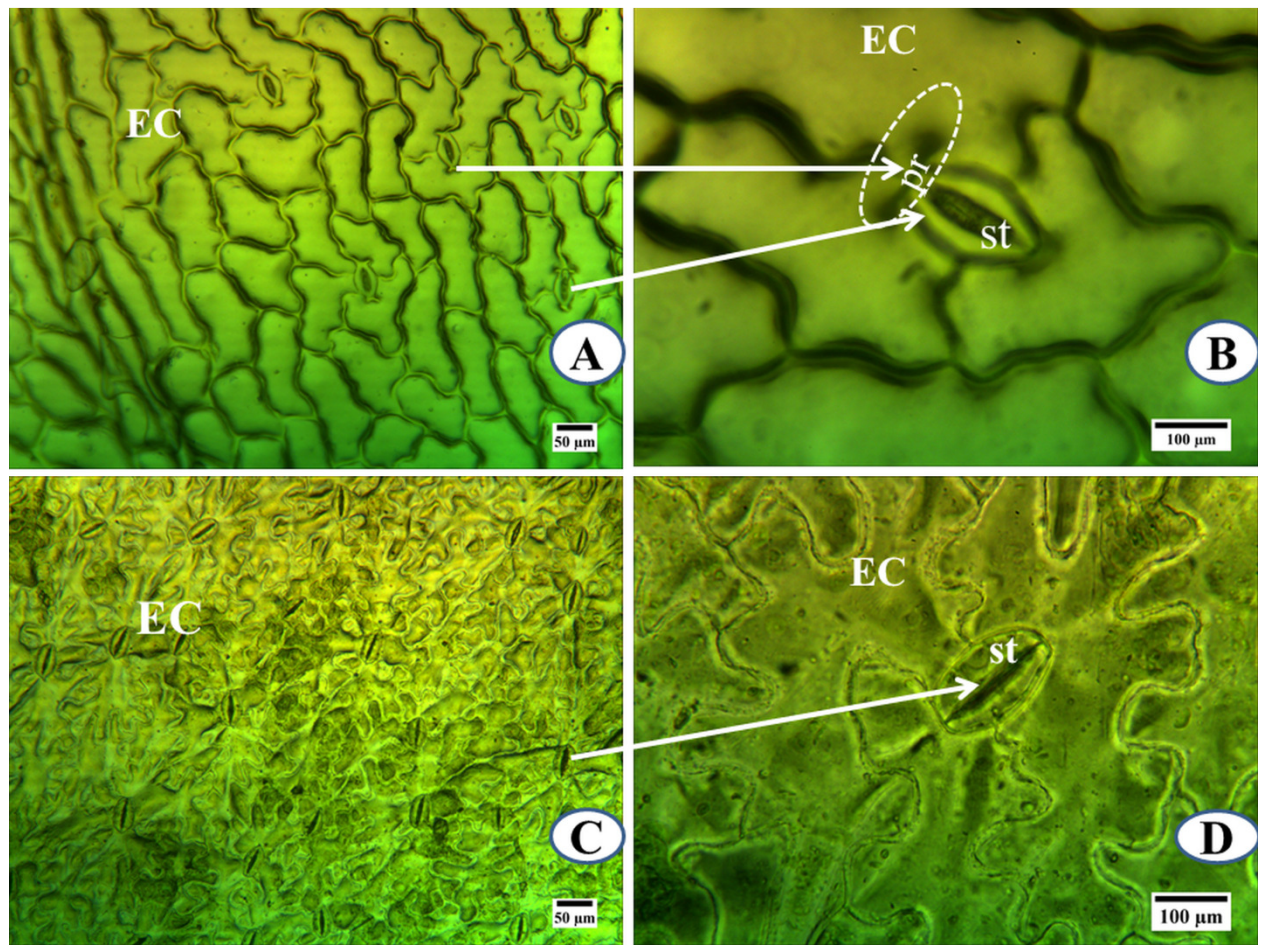

Fig. 3. Micrographs of upper (A \& B) and lower (C \& D) surfaces of $C$. argentea showing stomata (st); epidermal cell (EC) and protuberance $(\mathrm{pr})$ at the polar end of the stomata as viewed under the light microscope $[\times 400(\mathrm{~A}$ and $\mathrm{C}) ; \times 800(\mathrm{~B}$ and $\mathrm{D})]$ 
1132

Histochemical tests were used to detect and localize some chemical compounds present in the secretory organs of $C$. argentea (Fig. 5). The results showed a positive reaction with brownish coloration observed when the leaf was stained with $\mathrm{FeCl}_{3}$, confirming the presence of polyphenols (Fig. 5a). The presence of tannins in the leaf was evidenced by brownish-dots on the trichomes when stained with Toluidine blue reagent (Fig. 5b). Total lipids stained reddish orange with Sudan IV (Fig. 5c) while a blueblack coloration detecting starch was visible with iodinepotassium iodide stain (Fig. 5d). Fig. 5e is the untreated leaf as a control.
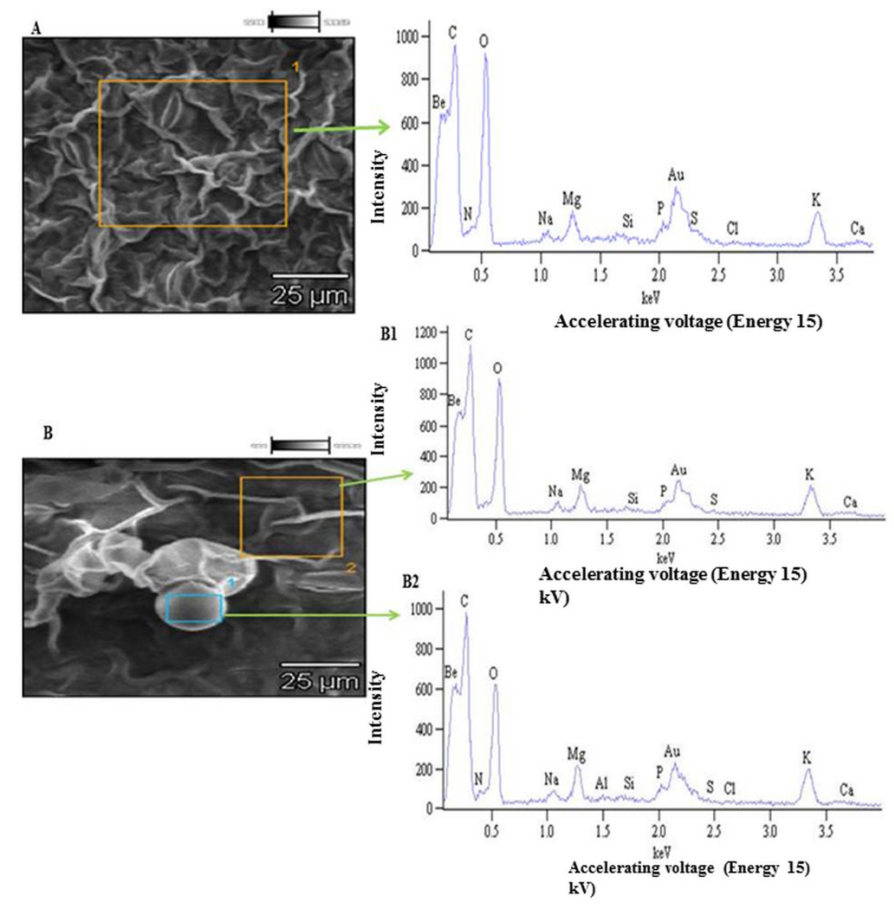

Fig. 4. Energy dispersive $\mathrm{X}$ ray showing elemental spectra of A- stoma; B- epidermis and glandular trichome. B1- spectra of epidermis and B2- spectra of capitate glandular trichome of C. argentea

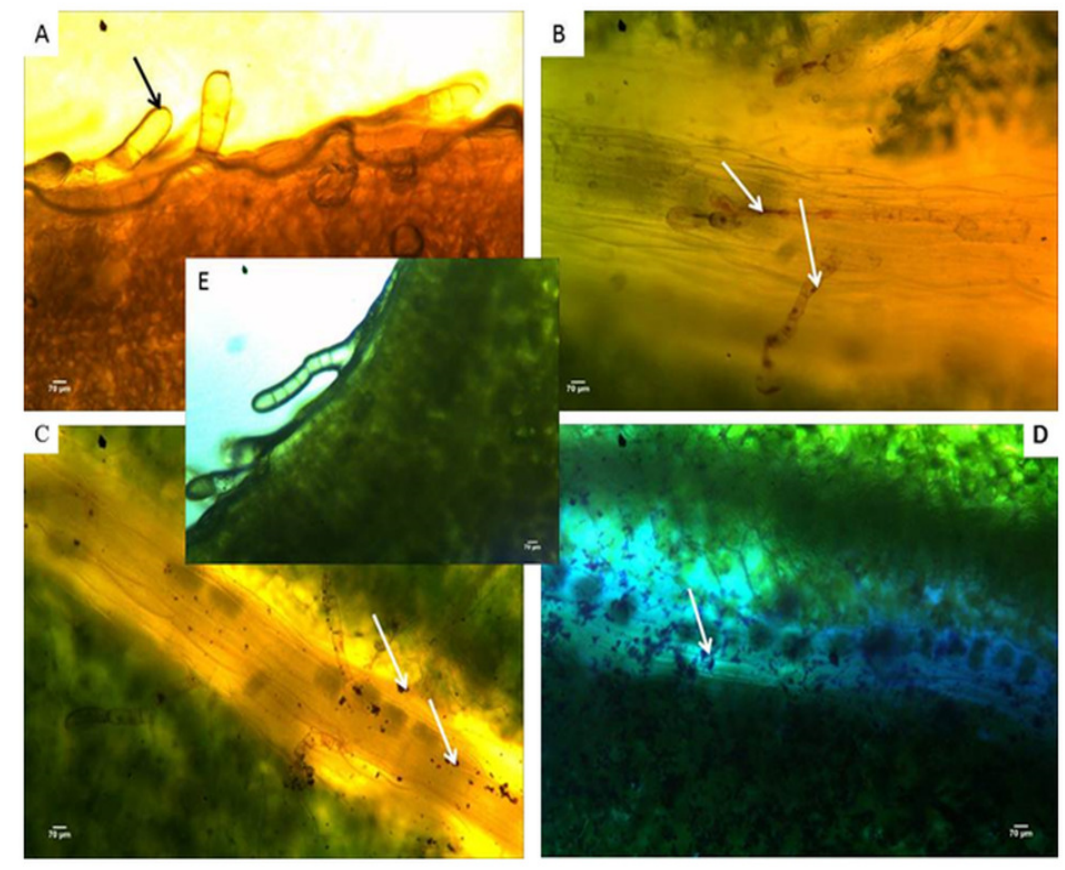

Fig. 5. Histochemical micrographs showing A- phenols; B- tannins; C-lipids; D-starch and E- control in C. argentea 


\section{Discussion}

Leaves provide a variety of anatomical features that are pivotal to solve some intrinsic issues at the generic level of classification (Guo et al., 2017; Ohikhena et al., 2017). In this study, the detailed ultrastructural features of the leaves of Celosia argentea could minimize the ambiguity caused by close-related species, overlapping features and ecological distribution. The abundant stomata distribution observed at the lower foliar epidermal surface of $C$. argentea has been reported by various researchers as a natural phenomenon in most dicotyledonous plant (Roelfsema and Hedrich, 2005; Zhigila et al., 2015). It is also thought to be a strategy employed by angiosperms in order to adapt to prevailing environmental conditions, to prevent excessive water loss (Anifat et al., 2017). Kim et al. (2010) reported that the long-term response of stomata to changes in the environment usually leads to production of new leaves, alteration in stomata size and stomata number per unit area. The plant used for this study was raised in a regulated environment free from harsh environmental conditions like excessive cold or heat (A temperature range between 25-27 ${ }^{\circ} \mathrm{C}$ was maintained in the green house), so the high mean density observed at the abaxial surface could be due to the characteristic behaviour of dicots or the conservation strategy of the plant to prevent water loss at the time of the day it was harvested. Stomata sense and integrate a range of environmental signals, including soil moisture and atmospheric carbon. Enlargement or reduction in stomata aperture has also been reported as one of the ways plant respond to their intrinsic and extrinsic environment. When unfavourable changes occur in the environment the plant sense this "stress", then transmit a signal to regulate stomata aperture (Israelsson $e t$ al., 2006). The anisocytic mixed with anomocytic stomata complex type that was observed in this study is similar to the findings of Ogundipe and Kadiri (2013).

Studies on the ultrastructural characters of the Amaranthaceae family have been well documented by various studies (Fank-de-Carvalho, 2013; Ogundipe and Kadiri 2013). However, apart from the reports of Illoh (1995), the presence of the protuberances at the polar ends of the stomata at the adaxial surface of $C$. argentea has not been accounted for. Protuberances were observed at the polar ends of the adaxial stomata of Celosia argentea in this study. Therefore, relying on the investigation carried out by Illoh (1995), this finding, could be considered as a diagnostic marker that distinguishes $C$. argentea from other species of the same genus and other member of the family.

Trichomes occur in different forms, sizes and are either single or multicellular structures. These structures can be glandular or non-glandular depending on their morphology and secretion ability (Huchelmann et al., 2017). The presence and absence of trichomes are used in delimiting plants at the generic level (Saheed and Illoh, 2010). Trichomes have long attracted the interest of scientific researchers based on their ability to protect the plant, synthesize and exude large amount of metabolites (Glas et al., 2012; Lotz et al., 2014). They protect the plant by regulating leaf temperature, excessive transpiration; create barriers against ultraviolet radiation and by secreting substances, which include among others, terpenes, phenolic, alkaloids and essential oils which serves as repellents to phytophagous insects (Xiao et al., 2017). The presence of glandular trichomes on the abaxial surface of the epidermis is in conformity with the reports of Illoh (1995) and Ogundipe and Kadiri (2013).

The energy dispersive $\mathrm{x}$-ray (EDX) revealed that the major elements present in the leaf and trichomes of $C$. argentea. Most of these elements observed, play important roles in physiological processes and plant nutrition. An element like potassium enhances the synthesis and translocation of carbohydrates, which causes thickening of plant cell wall; allowing the plant to remain upright, while magnesium, being the central atom in chlorophyll molecules is crucial for photosynthesis. The absence of chlorine on the adaxial surface of $C$. argentea leaf is similar to the findings of Sharaibi et al. (2017), who reported the presence of nitrogen only the adaxial surface of Agapanthus praecox. The presence of an element only one surface of the leaf under energy dispersive $x$-ray could be because of combination of elements when the percentage composition is being calculated by the EDX.

The presence of glandular trichomes on the leaf epidermis of $C$. argentea may be responsible among other specialized cells, for the production of chemical compounds reported for this species (Karthiyayini and Nithiya, 2015). The presence of starch grains, lipids, taninns and phenols on the leaves of $C$. argentea supports the results of Ranjan $e t$ al. (2013) on the histochemical screening of $C$. argentea leaves and stem. The observed pigmentation and coloration revealed by the histochemistry were mostly at the site where the trichomes are abundant. This may imply that the trichomes could be the major site for the production and secretion of chemical compounds in leaves of this species.

\section{Conclusions}

This is about the first report of presence of protuberances on the polar ends of the adaxial stomata of Celosia argentea leaves using SEM; a distinct ultra-feature that can be used for proper identification of $C$. argentea for medicinal purposes. The basic information on the epidermal characters and the histochemistry of $C$. argentea provided by this study when considered together could be relevant for the correct identification of this species from closely related species of Celosia to authenticate the quality and purity of this plant for medicinal and nutritional purposes. Our results could also add to the database for future reference of this species.

\section{Acknowledgements}

The authors acknowledge Govan Mbeki Research Development Centre, University of Fort Hare, South Africa, for their financial support. 
1134

\section{Conflict of Interest}

The authors declare that there are no conflicts of interest related to this article.

\section{References}

Adediran OA, Gana Z, Oladiran JA, Ibrahim H (2015). Effect of age at harvest and leaf position on the yield and nutritional composition of Celosia argentea. International Journal of Plant and Soil Science 5:359365.

Akyol Y (2014). The morphological and anatomical studies on endemic Crocusbiflorus. Miller. Pakistan Journal of Botany 46(2):573-578.

Albert S, Sharma B (2013). Comparative foliar micromorphological studies of some Baubinia (Leguminosae) species. Turkish Journal of Botany 37(2):276-281.

Anifat OB, Olaniran TO, Sefiu AS (2017). Leaf epidermal studies of some Solanum (Solanaceae) species in Nigeria. Phytologica Balcanica 23(1):55-63.

Brien TP, Feder N, McCully ME (1964). Polychromatic staining of plant cell walls by Toluidine Blue. Protoplasma 59(2):368-373.

Fank-de-Carvalho SM, Báo SN, Brasília B (2011). Anatomical and ultrastructural aspects of Amaranthaceae leaves from Chapada dos Veadeiros, Goiás State, Brazil. Acta Microscopica 18(Supp C):605-606.

Ferreira B, Falcioni R, Guedes LM, Avritzer SC, Antunes WC, Souza LA, Isaias RMS (2017). Preventing false negatives for histochemical detection of phenolics and lignins in PEG-Embedded plant tissues. Journal of Histochemistry and Cytochemistry 65(2):105-116.

Franks PJ, Beerling DJ (2009). Maximum leaf conductance driven by CO2 effects on stomatal size and density over geologic time. Proceedings of the National Academy of Sciences 106(25):10343-10347.

Glas JJ, Schimmel BC, Alba JM, Escobar-Bravo R, Schuurink RC, Kant MR (2012). Plant glandular trichomes as targets for breeding or engineering of resistance to herbivores. International Journal of Molecular Science 13(12):17077-17103.

Gottschalk W, Wolff G (2012). Induced mutations in plant breeding. Springer Science \& Business Media.

Guo C, Ma L, Yuan S, Wang R (2017). Morphological, physiological and anatomical traits of plant functional types in temperate grasslands alonga large-scale aridity gradient in northeastern China. Scientific Reports 7:40900.

Gupta S, Lakshmi AJ, Manjunath MN, Prakash J (2005). Analysis of nutrient and antinutrient content of underutilized green leafy vegetables.LWT-Journal of Food Science and Technology 38(4):339345.

Huchelmann A, Boutry M, Hachez C (2017). Plant glandular trichomes: natural cell factories of high biotechnological interest. Plant Physiology 175(1):6-22.

Illoh HC (1995). Foliar epidermis and petiole anatomy of four species of Celosia L. in Nigeria. Feddes Repertium 106(1-5):15-23.

Israelsson M, Siegel RS, YoungJ, Hashimoto M, Iba K, Schroeder JI (2006). Guard cell $\mathrm{ABA}$ and $\mathrm{CO}_{2}$ signaling network updates and $\mathrm{Ca}^{2+}$ sensor priminghypothesis. Current Opinion in Plant Biology 9(6):654-663.
Iwu MM (2014).Handbook of African medicinal plants. CRC Press.

Kantachot C, Chantaranothai P, Thammathaworn A (2007). Contribution to the leaf anatomy and taxonomy of Thai Myrtaceae. Tropical Natural History 7(1):35-45.

Karthiyayini R (2015). Nithiya. Pharmacognostic and preliminary phytochemical studies of Celosia argentea L. Leaf International Journal of Pharmacy and Pharmaceutical Research 7(2):237-239.

Kim TH, Böhmer M,Hu H, Nishimura N, SchroederJI(2010). Guard cell signal transduction network: advances in understanding abscisic acid, $\mathrm{CO}_{2}$ and $\mathrm{Ca}_{2}+$ signaling. Annual Review of Plant Biology 61:561-591.

Krouk G,Lacombe B, Bielach A, Perrine-Walker F, Malinska K, MounierE, ... Ljung K (2010). Nitrate-regulated auxin transport by NRT1. 1 defines a mechanism for nutrient sensing in plants. Developmental Cell 18(6):927-937.

Lotz LAP, Van De Wiel CCM, Smulders MJM, Prota N, Bouwmeester HJ, Jongsma MA (2014). Genetically modified crops and sustainable agriculture: A proposed way forward in the societal debate. NJAS Wageningen Journal of Life Sciences 70:95-98.

Metcalfe CR, Chalk L (1969). Anatomy of the dicotyledons: Vol 1. Systematic anatomy of leaf and stem, with a brief history of the subject. Oxford, Clarendon Press.

Molehin OR, Adefegha SA, Oboh G, Saliu JA, Athayde ML, Boligon AA (2014). Comparative study on the phenolic content, antioxidant properties and HPLC fingerprinting of three varieties of Celosia species. Journal of Food Biochemistry 38(6):575-583.

Momin RK, Kadam VB (2011). Histochemical investigation of different organce of genus Sesbania of Marathwada region in Maharashtra. Journal of Phytology 3:52-54.

Ogundipe OT, Kadiri AB (2013). Comparative foliar epidermal morphology of the West African species of Amaranthaceae Juss. Feddes Reperterium 123(2):97-116.

Ogungbenle HN, Otemuyiwa FF (2015). Food properties and amino acid composition of Celosia spicata leaves. Advances in Analytical Chemistry 5(1):1-7.

Ohikhena FU, Wintola OA, Afolayan AJ (2017). Micromorphological studies of the Loranthaceae, Phragmanthera capitata (Sprengel) Balle. Journal of Botany 5603140.

Okpako E, Ajibesin KK (2015). Antimicrobial activity of Celosia argentea L . American Journal of Research Communication 3(3):123-133.

Ranjan BR, Deokule SS (2013). Pharmacognostic and phytochemical investigation of Celosia argentea Linn. International Research Journal of Pharmacy 4:138-144.

Roelfsema MR, Hedrich R (2005). In the light of stomatal opening: new insights into 'the Watergate'. New Phytologist 167(3):665-691.

Sá RD, Santana AS, Silva FC, Soares LAL, Randau KP (2016). Anatomical and histochemical analysis of Dysphania ambrosioides supported by light and electron microscopy. Revisa Brasileira de Farmacognosia 26(5):533543.

Saheed SA, Illoh HC (2010). Important morphological characters in several species of Cassiinae (Leguminosae) in South-Western Nigeria. Notulae Scientia Biologicae 3(2):47-56.

Schliemann W, Cai Y, Degenkolb T, Schmidt J, Corke H (2001). Betalains 
of Celosia argentea. Phytochemstry 58(1):159-165.

Sereena K, Sreeja K (2014). Comparative anatomical and histochemical studies of Achyranthes aspera L. and Cyathula prostrata L. blume, source plants of the drug Apamarga. International Journal of Pharmacy and Pharmaceutical Research 6(3):658-671.

Sharaibi OJ, Afolayan AJ (2017). Micromorphological characterization of the leaf and rhizome of Agapanthus praecox subsp. praecox Willd. (Amaryllidaceae).Journal of Botany doi.org/10.1155/2017/3075638.

Sharma P, Vidyasagar G, Singh S, Ghule S, Kumar B (2010). Antidiarrheal activity of leaf extract of Celosia argentea in experimentally induced diarrhea in rats. Journal of Advanced Pharmaceutical Technology and Research 1(1):41-48.

Varadharaj V, Muniyappan J (2017). Phytochemical and phytotherapeutic properties of Celosia species - a review. International Journal of Pharmacy and Pharmaceutical Research 9(6):802-825.

Wu QB, Wang Y, Guo M (2011). Triterpenoid saponins from the seeds of
Celosia argentea and their anti-inflammatory and antitumor activities Chemical and Pharmaceutical Bulletin 59(5):666-667.

Xiao K, Mao X, Lin Y, Xu H, Zhu Y, Caib Q, ... Zhang J (2017). Trichome, a functional diversity phenotype in plant. Molecular Biology 6:183-189.

Xue QA, Sun L, Guo ML, WangY,ZhangG, WangXK(2011). Two new compounds from Semen celosiae and their protective effects against CCl4induced hepatotoxicity. Natural Product Research 25(8):772780.

Zheng XI, Xing FW (2009). Ethnobotanical study on medicinal plants around Mt. Yinggeling, Hainan Island, China. Journal of Ethnopharmacology 124(2):197-210.

Zhigila DA, Sawa FBJ, Aluko TA, Oladele FA, Abdul Rahaman AA (2015). Leaf epidermal anatomy in five varieties of Capsicum annuum L. Solanaceae. American Journal of Experimental Agriculture 5(4):392399. 